\title{
Understanding customer-supplier chains: - conflict resolution psychology \& civil litigation
}

\begin{abstract}
Developing the theme of how psychology and organisational theory can influence the practice of civil litigation, this paper addresses how the concept of 'customersupplier' chains can apply to conflict resolution in civil compensation claims. The authors unique experience of psychology, quality management and civil claims, offers an innovative insight into how conflicts occur and can be resolved, and how advanced communication skills can be used intentionally to produce 'win-win' solutions to legal and medico-legal problems.
\end{abstract}

Keywords: Customer-supplier chains, psychology, conflict resolutions, impartiality, micro skills, communications, intentionality
Volume 7 Issue 2 - 2018

Hugh CH Koch,' Beena Parmar,' Justin

Savage, ${ }^{2}$ Nicky Hartigan ${ }^{2}$

'Clinical Psychologist and Professor, Birmingham City University

\&Stockholm, Sweden

${ }^{2}$ Clinical Psychologist, Hugh Koch Associates, England

Correspondence: Hugh Koch, Chartered Psychologist, Hugh Koch Associates, Cheltenham,Visiting Professor, Faculty of Law, Birmingham City University \& Stockholm University, Sweden, Tel +0I242-2637I5, Email hugh@hughkochassociates.co.uk

Received: November 05, 2017 | Published: March 27, 2018

\section{Introduction to the interface between psychology \& law}

Recent $\operatorname{articles}^{1-3}$ have outlined how the many branches of psychology can influence civil law processes there are in relation to the organisational culture of courts and justice, claimant experience, expert experience and experience of judges, barristers and lawyers. Organisational concepts like Continuous Quality Improvement and Therapeutic Jurisprudence, (a positive approach to the delivery of justice), have also been recently considered. ${ }^{4}$ This innovative paper addresses these concepts further, both psychological and organisational, in the context of two crucial ideas: customer-supplier chains and conflict resolution.

\section{The psychology of customer-supplier chains}

In civil litigation, interactions occur between a variety of people, both claimant and professionals, to reach an outcome or settlement for the claimant and insurer. It involves and necessitates coordination and collaboration between each other, involving multi-factorial processes. Many of the exchanges may involve people who have little or no knowledge or interest in the other 'players' in the medico-legal supply chain. It is necessary to integrate these several processes and disseminate the awareness and knowledge of these processes to all involved. It attests to the success of civil litigation in the UK that the medico-legal supply chain can cope with change, is resilient, and both claimant and insurer-centric. Those whose career is fully in this area develop flexible supply chains, continuously anticipating and adjusting to 'crises', discontinuities and focus, especially, on ultimate and multiple customer-centricity, ${ }^{5}$ whilst maintaining a responsibility to the court.

\section{What is the medico-legal supply chain?}

Two images can clearly illustrate how the supply chain operates in civil litigation. We are all 'customers' (i.e. expecting a service of high quality from another person(s) and 'suppliers' (i.e. expected to provide a high-quality service to someone). However, we typically are concerned and interested in one customer and one supplier directly to each side of our own activities as reflected in Figure 1 below. This figure indicates how, for example, an instructing solicitor has to manage his relationship with both his client and an expert Figure 2.

\begin{tabular}{|c|c|c|c|c|c|}
\hline C & $c$ & f & $S$ & r & $S$ \\
\hline aima & & & & & $\mathrm{Co}$ \\
\hline
\end{tabular}

Figure I This figure indicates how, for example, an instructing solicitor has to manage his relationship with both his client and an expert.

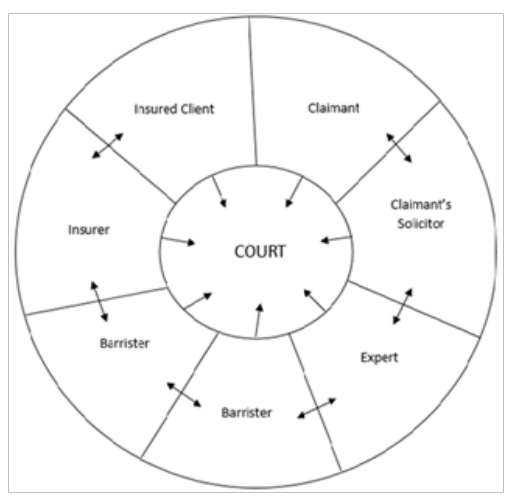

Figure 2 Illustrates to a certain extent many of these relationships, interaction and multiplicity of the many 'customer-supplier' chains seen in civil litigation.

\section{Positive culture in civil litigation}

Whether using the professional and ethical language of any one profession (e.g. lawyer, psychologist, barrister) or adopting the language used in quality management practices ${ }^{6,7}$ it is widely acknowledged that there are significant benefits for a strong culture of beliefs, values and visions which are both intuitive and supported by psychological and social science. Positive values including the following (Figure 3): 


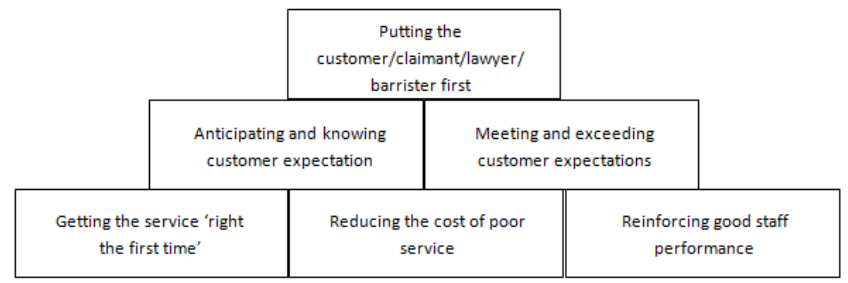

Figure 3 Positive values in civil law.

\section{The skills of confrontation: supporting while challenging conflict}

It is necessary to confront discrepancies of information, opinions and values in civil litigation. An understanding of confrontation skills is crucial including:

i. Increased ability to identify incongruity, discrepancies, or mixed messages in behaviour, thought, feelings, or meanings.

ii. Ability to increase explanation and/or resolution of conflict and discrepancies.

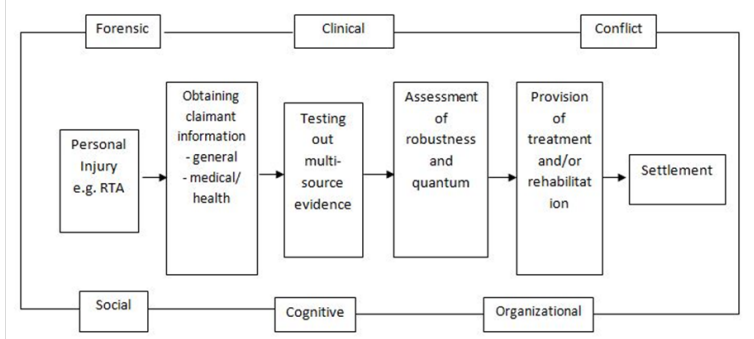

Figure 4 The main process steps involving medico-legal experts plus the several branches of psychology.

\section{Positive, advanced communication skills}

In addition to being an effective and socially skilled communicator, it is important that each person involved in the civil litigation trail can manage the following circumstances sensibly, effectively and wherever possible to mutual benefit with the other person(s) involved.

i. Frustration with incomplete or absent information

ii. Difficulty getting access to another person

iii. Receiving information to confirm an arrangement or task i.e. iii. Ability to utilize confrontation skills as part of mediation and conflict resolution.

iv. Intentionality is the goal to eliminate conflict and inaction and lack of understanding. Becoming aware of issues of incongruity and working to resolve them including labelling the incongruity through non-judgemental confrontation by using the following skills:

v. Identify the incongruity or conflict in the evidence

vi. Through the use of questioning and other listening skills, draw out the specifics of the conflict or mixed messages. One at a time, give attention to each part of the mixed message, contradiction, or conflict. It is important at this stage to be non-judgmental and non evaluative - aim for facts, allowing a non-judgmental stance to be reflected in tone of voice and body language.

vii. Periodically summarize the several dimensions of the incongruity. As a result, the importance of being non-judgmental and including a check-out as a final part of the confrontation cannot be overstressed.

viii. At any/all stages of the medico-legal trail, it is possible to move towards mutual acceptance, generation of new solutions and opinions (Figures $4 \& 5$ ).

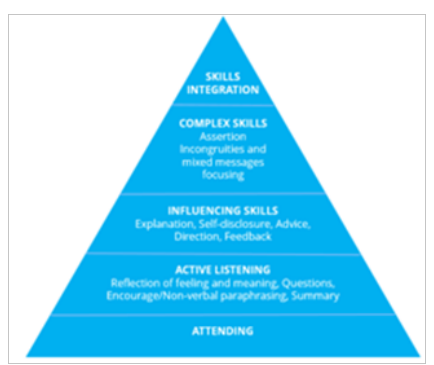

Figure 5 Micro skills of Effective Communication. ${ }^{8}$

closing the loop

iv. Handling differences of opinion in conditions of low anxiety/low perceived crisis

v. Handling differences of opinions in conditions of high anxiety/ high perceived crisis

vi. Understanding 'win-win' discussions and solutions

vii. Developing and maintaining long term mutually beneficial working relationships as appropriate (Figure 6).

Figure 6 The skills need to reduce problems can increasingly be used 'intentionally' and result in 'win-win' situations.

\begin{tabular}{|c|c|}
\hline \multicolumn{2}{|c|}{ Typical Problem } \\
\hline i. & $\begin{array}{l}\text { Expert Witness - Claimant } \\
\text { Differences of opinion in interview or report; discussion of sensitiv } \\
\text { personal information/history; assessment of severity of claimant } \\
\text { distress; claimant resilience assessment; confusing language used in } \\
\text { report. }\end{array}$ \\
\hline ii. & $\begin{array}{l}\text { Expert Witness - Instructing Solicitor } \\
\text { Dealing with communicating claimant news via solicitor to expert } \\
\text { and perceived criticism; solicitor's ability to act as 'gate-keeper' or } \\
\text { 'middle man' between claimant and expert; inappropriate pressure } \\
\text { on expert to alter opinion. }\end{array}$ \\
\hline
\end{tabular}

\section{Potential Solution}

Listening to claimant; acknowledge their concerns; accommodating new information; maintaining expert opinions whilst simultaneous being seen to take on board claimant's comments.

Listening to each other's viewpoints; Establishing the opinion as robust and unlikely to alter except with new evidence. Maintaining expert's ultimate responsibility 'to the court'. 
Table continued...

iii. Case Conference Discussion

Pressure on expert to alter opinion and be partial, rather than impartial; ensuring expert has fully considered all relevant evidence and ambiguities.

iv. Part 35 Questions and Responses

Partial questioning from defendant with pressure to alter opinion on severity and attribution.

v. Expert - Expert Joint Statement

Following clarification of each expert's opinion, appraisal of ambiguity and disagreement between experts.

vi. Court Hearing

Access by all to all evidence - clarification of partiality of points of view of/and differing emphasis of any party.

vii. Post Hearing Conflict

Even once the Court has come to a judgment, there may still be conflict between a claimant/lawyer/expert over the outcome and especially the costs.
Maintenance of Impartiality Skills ${ }^{9}$

Effective and mutual listening to all available evidence. Separating ambiguity and appropriate alternation of opinion from perceived criticism.

Maintenance of Impartiality Skills ${ }^{10}$

Management of logicality compared to perceived criticism.

Highly logical and effective communication between experts and willingness to consider appropriate range of opinions. " Willingness to consider new evidence.

Importance of professional to accommodate and consider all evidence and range of opinion and to help the court arrive at most robust opinion.

An understanding by all parties of the complexity of litigation and the role of expert evidence.

\section{Conclusion}

This paper continues the first author's theme in the past 1-2 years of applying psychology and organisational management ideas to the practice of civil litigation and especially medico-legal aspects. Professionals, whether they be experts, solicitors, barristers or judges, encounter conflict regularly in their day-to-day work and have differing levels of communication skills and emotional regulation abilities. $^{12}$ This paper emphasises the importance of developing a greater 'intentionality' in which the professional knows and can elect, consciously, to apply a particular skill to reduce interpersonal tension and conflict in order to arrive, more often, at a 'win-win' solution. The idea of the Single Joint Expert (SJE) originally suggested within the Civil Procedure Rules ${ }^{13}$ back in 1998/9 has never taken off to any substantial extent. When occasionally approved as an S.J.E, such experts experience a different type of communication and impartiality. This role may become more frequent. In the meantime, experts alongside all the other people involved in civil litigation need to understand customer-supplier chains and their effects on conflict resolution. This paper has applied the concept of customer-supplier chains to the specific area of civil claims within personal injury in a UK-based population. Further research could usefully address their specific areas in more detail and with a larger sample, which could also include self-report or psychometric data. It could also usefully address a criminal law sample to compare and contrast fluidity between civil and criminal populations.

\section{Acknowledgment}

None.

\section{Conflict of interest}

None.

\section{References}

1. Koch HCH, Hampton N, Midgley S, et al. Current Developments on the Interface of Psychology and Law in Civil Justice: Reconciling Law, Science \& Policy. J Psychol. 2017;2(2):83-85.

2. Koch HCH. The Psychology of Justice: The Interface Between Psychology and Civil Law. Mathews Journal of Case Reports. 2017;2(2):030.

3. Koch HCH, Elson PA, Dicks M. Understanding Civil Justice: The Role of Cognitive Psychology in Civil Law. 2017. MOJPH.

4. Koch HCH, Diesen C. Therapeutic Jurisprudence - Continuous Quality Management and Positivity in the Civil Justice System in Sweden and UK. MOJ Public Health. 2017;5(1):00118.

5. Koch HCH. Legal Mind: Contemporary Issues in Psychological Injury and Law. Expert Witness Publications. Manchester. 2016.

6. Oakland J. Total Quality Management. Heinemann. Oxford. 1989.

7. Koch HCH. Conflict Resolution Psychology \& Civil Litigation. PIBULJ, November. 2017.

8. Ivey A, Ivey MB. Intentional Interviewing and Counselling. Brooks Cole, London. 2007.

9. Koch HCH. Impartiality of medico-legal experts. Expert Witness Institute Newsletter. Spring. 2017

10. Koch $\mathrm{HCH}$, Elson PA. Impartiality of Expert Witness: Defining and measuring this construct. Exp. Wit. J. Summer. 2017.

11. Hetherton J, Payne L, De Haro L. The Joint Statement Process: Differing opinions on a potential case of Post Traumatic Stress Disorder. Mathews Open Access Journals. 2017;2(5004):1-3.

12. Koch $\mathrm{HCH}$, Humphreys $\mathrm{K}$, Byram V, et al. Communication Psychology in Civil Law: The micro skills of Impartiality and Neutrality. Expert Witness Journal. Autumn. 2017.

13. Ministry of Justice. The Civil Procedure Rules. 3132.L17. London. 1998 